\title{
Effects of Gas Temperature and Particulate Water on Rabbit Lungs During Ventilation
}

\author{
ELIZABETH JOHN, ${ }^{(40)}$ RUFINO ERMOCILLA. JAMES GOLDEN, RICK CASH, MICHAEL MCDEVITT, \\ AND GEORGE CASSADY \\ Division of Perinatal Medicine. Department of Pediatrics, Departments of Pathologv and Biomedical Engineering, \\ University of Alabama in Birmingham, Birmingham, Alabama. USA
}

\begin{abstract}
Summary
Anesthetized young rabbits were ventilated for $6 \mathrm{hr}$ at $20 \mathrm{~cm}$ $\mathrm{H}_{2} \mathrm{O}$ peak airway pressure using air nebulized with water at $22^{\circ} \mathrm{C}$ (cold nebulized group, $n=11$ ), at $36^{\circ} \mathrm{C}$ (warm nebulized group, $n$ $=11$ ) and humidified air at $36^{\circ} \mathrm{C}$ (warm humidified group, $n=10$ ). Their biochemical status during ventilation and pulmonary morphology at autopsy were compared to those of ten control rabbits. Both nebulized groups had particulate water in the inspired air and water of condensation in the endotracheal tube.

The rabbits ventilated with warm humidified air and the control group breathing spontaneously maintained their blood pressure and $\mathrm{pHa}$ within physiologic range. Rabbits ventilated with air nebulized with water at 22 and $36^{\circ} \mathrm{C}$ had a significant decline in mean blood pressure $(96 \mathrm{~mm} \mathrm{Hg} \rightarrow 61 \mathrm{~mm} \mathrm{Hg}$ in cold nebulized and $91 \mathrm{~mm} \mathrm{Hg} \rightarrow 61 \mathrm{~mm} \mathrm{Hg}$ in warm nebulized) and mean pHa $(7.43 \rightarrow 7.23$ in cold nebulized and $7.42 \rightarrow 7.31$ in warm nebulized). All rabbits in the control and warm humidified groups survived the study whereas 9 of 22 in the nebulized groups died before completion of study $(P<0.005)$.

Morphometric analysis revealed a significant increase in the mean vascular wall thickness in both nebulized groups of rabbits when compared to that in the control and warm humidified groups $(P<0.05)$. The cold nebulized group also had significantly less air space and correspondingly more interstitial thickness and intraalveolar edema $(P<0.05)$ compared to control and warm humidified groups. These findings of pulmonary parenchymal damage in rabbits ventilated with air containing particulate water and the greater degree of both physiologic and anatomic change evident in the cold nebulized animals suggest that particulate water and low inspired air temperature may contribute to the genesis of pulmonary damage during intermittent positive pressure ventilation.
\end{abstract}

\section{Speculation}

The phenomenon of reflex pulmonary hypertension following instillation of small quantities of fresh water to the lung (5) might occur even if miniscule amounts of particulate water are delivered during intermittent positive pressure ventilation. Particulate water in inspired air could therefore play a role in the pulmonary parenchymal damage seen in babies treated with intermittent positive pressure ventilation. Failure to maintain temperature of the inspired air at body temperature during intermittent positive pressure ventilation (25) may also have a deleterious effect in the human infant.

The observations made by Northway et al. (29) in humans and deLemos et al. (7) in lambs suggest that use of high concentrations of oxygen during intermittent positive pressure ventilation (IPPV) is responsible for parenchymal changes seen in lungs of humans subjected to IPPV. More recent studies suggest that barotrauma may be a contributing factor $(36,37)$. In a previous study, we demonstrated lesions similar to those described by deLemos et al.
(7) and Nash et al. (26) in lungs of healthy young anesthetized rabbits subjected to IPPV with air nebulized with water at $36^{\circ} \mathrm{C}$ and suggested that pressures as low as $20 \mathrm{~cm} \mathrm{H}_{2} \mathrm{O}$ may play a role in the production of these lesions (20).

The nasal passages, mouth, and pharynx of the intact animal have the capacity to adjust the temperature and humidity of the inspired air and remove air-borne particles from it (32). The need to deliver moist gas when these passages are bypassed by an endotracheal tube or tracheostomy tube has been emphasized repeatedly $(3,8,10,15,18,38)$, but well-documented studies defining the optimum temperature of air and characteristics of water to be delivered during IPPV are few $(14,15,18)$. In this study, we examined the pulmonary effects of variations in water content or state and temperature of the inspired air in rabbits on IPPV.

\section{MATERIALS AND METHODS}

Forty-two New Zealand White rabbits, between 6 and 12 wk of age and weighing 1400 to $3000 \mathrm{~g}$ were randomly allotted to four groups. The control group consisted of 10 rabbits who were lightly anesthetized with $20 \pm 5 \mathrm{mg} / \mathrm{kg}$ of intravenous (IV) pentobarbitone sodium and tracheotomized. A $2.5 \mathrm{~mm}$ Portex tube was positioned above the carina. Catheters (inside diameter $=0.034$ inches) were placed in the right carotid artery and jugular vein. The venous catheter was advanced to lie in the intrathoracic part of the inferior vena cava.

The experimental group consisted of 32 rabbits in whom all procedures were done as in controls except that these rabbits were ventilated with air using a pressure-controlled, flow-regulated ventilator (Bird Mark 7). The peak airway pressure was maintained at $20 \mathrm{~cm} \mathrm{H}_{2} \mathrm{O}$, the rate was maintained at 26 to $28 / \mathrm{min}$, inspiratory:expiratory time ratio was maintained at $1: 2$, and end expiratory pressure was maintained at $1 \frac{1}{2} \mathrm{~cm} \mathrm{H} 2 \mathrm{O}$

The air delivered to the proximal airways in the ventilated animals was moistened and heated in three different ways. In 11 rabbits, subsequently referred to as the "cold nebulized group," the air was circuited through an Ohio Deluxe nebulizer at room temperature $\left(22^{\circ} \mathrm{C}\right.$ measured close to the proximal airway). In 11 other rabbits, water was heated in the nebulizer, and air was circuited through it to provide a proximal airway temperature of $35-36^{\circ} \mathrm{C}$. These animals are subsequently referred to as the "warm nebulized group." In both cold and warm nebulized groups, particulate water was present in the air delivered. Ten other rabbits were ventilated with air circuited through the nebulizer at room temperature and subsequently heated to $36^{\circ} \mathrm{C}$ at a point close to the proximal airway. This group of rabbits is subsequently referred to as the "warm humidified group." On the basis of previously described performance characteristics of these nebulizers $(21)$, it was anticipated that air passed through a nebulizer at room temperature would be $75 \%$ saturated with water at $37^{\circ} \mathrm{C}$ and supersaturated $(120 \%)$ at $37^{\circ} \mathrm{C}$ when a heated nebulizer was used.

Central venous pressure (CVP) and carotid artery pressure were 
measured by means of a Statham P23 ID strain gauge pressure transducer and recorded (Gould Brush 2400) using the midthorax as the reference point. Airway pressure, obtained with reference to the esophageal pressure using a differential pressure transducer (Statham 13ITC with equal volume adapter), was considered to be the transpulmonary pressure. Tidal volume was obtained by integrating flow through a Fleisch pneumotach '00' pneumotachograph. Dynamic lung compliance was calculated using the standard formula and expressed as a percentage of the initial value. Pressure deflections were calibrated with a water manometer, whereas volume deflections were calibrated by injecting known volumes of air at specific flow rates through the pneumotachograph. Response was linear in the range studied ( 1 to 6 liters/ min). The recorder was calibrated before each experiment, and the reference line was checked periodically during the course of the experiment; there was no drift. The rabbits were maintained under light anesthesia for $6 \mathrm{hr}$ by intermittent administration of 5 to $10 \mathrm{mg}$ of pentobarbitone sodium. Deep body temperature was maintained between 37 and $39^{\circ} \mathrm{C}$ using a Westinghouse reflector infrared heater. They were lightly restrained during the study period, but the position was changed every $\mathrm{hr}$.

Rabbits that survived the 6-hr study were sacrificed with IV pentobarbitone sodium (uthol). An additional six rabbits, randomly selected during the 8-month study, were sacrificed on receipt. Partial autopsy was performed in all, and the thoracic cavity was examined for evidence of air leak and hemorrhage. The lungs were removed intact and fixed at residual volume in $10 \%$ formaldehyde in $0.9 \%$ sodium chloride. A wk later, 4 to $5 \mu \mathrm{m}$ sections were obtained from the left lower lobe and stained with hematoxylin and eosin.

The Leitz Texture Analysis System (TAS), a microscope-based image analysis system, was programmed to measure the area occupied by airspace, edema fluid, and interstitium using the concept of gray value resolution (34). Four hundred adjacent high-power fields $(240 \times 240 \mu \mathrm{m})$ were analyzed in each section.
Small pulmonary arteries with an external diameter between 30 and $200 \mu \mathrm{m}$ were also examined, and the vascular wall thickness was measured. A total of 571 pulmonary arteries, evenly distributed between the four groups, were studied. The circular mask of the TAS was adjusted to occupy the arterial lumen, the rim of the circle extending to the muscle layer (Fig. I, circle A). With the center fixed, the mask was enlarged to include the narrowest section of the vascular wall (Fig. 1, circle B). The serosa was not included in the measurement. The TAS was programmed to calculate the diameter of the two circles. The vascular wall thickness was obtained using the formula, wall thickness $=(D-d) / 2$, where $D$ is the diameter of the larger circle, and $d$ is the diameter of the smaller circle and was expressed as a percentage of the outer diameter (D).

Grouped data were compared using Student's $t$ test. Responses of rabbits to the experimental procedure were studied using a paired $t$ test; differences in outcome were analyzed using the $\chi^{2}$ test with Yates correction. Differences were considered to be significant at a $P$ value of less than 0.05 .

\section{RESULTS}

Age, weight, and sex distribution were similar in the four groups of rabbits. Baseline data obtained after anesthesia and surgery are shown in Table 1. Mean blood pressure, hematocrit, arterial carbon dioxide tension, arterial $\mathrm{pH}(\mathrm{pHa})$, and calculated bicarbonate were similar in the four groups. Mean CVP and arterial oxygen tension were also similar (Table 1).

\section{STATUS DURING STUDY (TABLE I)}

A drop in mean carotid artery pressure was noted in all groups. Mean hematocrit decreased in all groups, except the cold nebulized group. A significant decrease in calculated bicarbonate in all groups was greatest in cold nebulized group. However, mean pHa

\section{VASCULAR WALL THICKNESS USING LEITZ TEXTURE ANALYSIS METHOD}

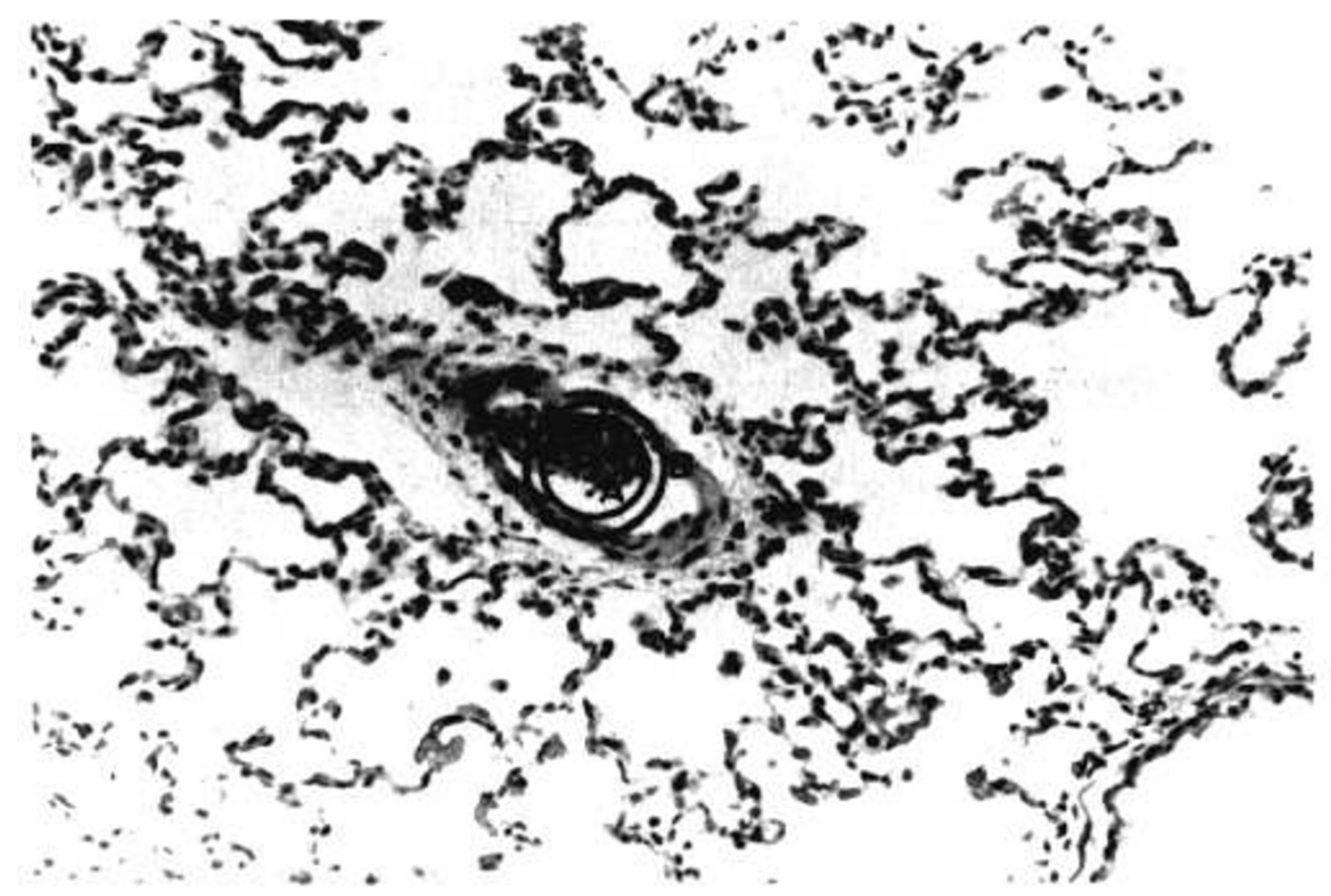

Fig. 1. Determination of vascular wall thickness using the Leitz Texture Analysis System. $A$, vascular lumen, the rım touching the muscle layer; $B$, vascular size. 
Table 1. Physiologic status before and after study and pulmonary morphometry at autopsy

\begin{tabular}{|c|c|c|c|c|c|c|c|c|c|c|c|c|}
\hline \multirow[b]{3}{*}{ Groups } & \multirow[b]{3}{*}{$\begin{array}{l}\text { No. } \\
\text { lived }\end{array}$} & \multicolumn{7}{|c|}{$\begin{array}{l}\text { Physiologic status } \\
\text { Initial and final values }\end{array}$} & \multicolumn{4}{|c|}{ Pulmonary morphometry } \\
\hline & & \multirow[b]{2}{*}{$\mathrm{CVP}^{2}$} & \multirow[b]{2}{*}{ BP } & \multirow[b]{2}{*}{ HCT } & \multirow[b]{2}{*}{$\mathrm{PaO}_{2}$} & \multirow[b]{2}{*}{$\mathrm{PaCO}_{2}$} & \multirow[b]{2}{*}{$\mathrm{pHa}$} & \multirow[b]{2}{*}{$\mathrm{HCO}_{3}^{-}$} & \multicolumn{2}{|c|}{ Vascular } & \multicolumn{2}{|c|}{ Parenchyma } \\
\hline & & & & & & & & & $\begin{array}{l}\text { Wall thickness } \\
\text { as \% outer } \\
\text { diameter }(n)\end{array}$ & $\begin{array}{l}\text { Air space } \% \\
\text { total area }\end{array}$ & $\begin{array}{l}\text { Interstit } \% \\
\text { total area }\end{array}$ & $\begin{array}{l}\text { Edema } \% \\
\text { total area }\end{array}$ \\
\hline Control & $\frac{10}{10}$ & $\begin{array}{l}1.0 \pm 0.4^{3} \\
1.5 \pm 0.4\end{array}$ & $\begin{aligned} 104 & \pm 4.7 \\
87 & \pm 3.2^{4}\end{aligned}$ & $\begin{array}{l}35 \pm 0.8 \\
31 \pm 1.4\end{array}$ & $\begin{array}{l}61 \pm 2.5 \\
71 \pm 4.3\end{array}$ & $\begin{array}{l}35 \pm 1.5 \\
29 \pm 1.5^{4}\end{array}$ & $\begin{array}{l}7.45 \pm 0.02 \\
7.46 \pm 0.02\end{array}$ & $\begin{array}{l}23 \pm 0.9 \\
20 \pm 0.8^{4}\end{array}$ & $\begin{array}{c}11.8 \pm 0.54 \\
(148)\end{array}$ & $62 \pm 2.0$ & $35 \pm 1.4$ & $3 \pm 0.8$ \\
\hline Cold nebulized & $\frac{5}{11}^{4}$ & $\begin{array}{l}1.6 \pm 0.6 \\
2.0 \pm 0.7\end{array}$ & $\begin{array}{l}96 \pm 4.9 \\
61 \pm 9.9^{4}\end{array}$ & $\begin{array}{l}35 \pm 1.2 \\
34 \pm 1.5\end{array}$ & $\begin{array}{l}60 \pm 3.3 \\
53 \pm 6.8\end{array}$ & $\begin{array}{l}38 \pm 2.1 \\
44 \pm 6.0\end{array}$ & $\begin{array}{l}7.43 \pm 0.02 \\
7.23 \pm 0.06^{4}\end{array}$ & $\begin{array}{l}24 \pm 1.0 \\
17 \pm 1.3^{5}\end{array}$ & $\begin{array}{l}13.2 \pm 0.46^{4} \\
\quad(135)\end{array}$ & $49 \pm 3.1^{5}$ & $43 \pm 3.0^{4}$ & $8 \pm 2.2^{4}$ \\
\hline Warm nebulized & $\frac{8}{11}$ & $\begin{array}{l}2.0 \pm 0.9 \\
2.2 \pm 0.9\end{array}$ & $\begin{array}{l}91 \pm 7.3 \\
61 \pm 8.1^{4}\end{array}$ & $\begin{array}{l}34 \pm 1.0 \\
30 \pm 1.4\end{array}$ & $\begin{array}{l}57 \pm 4.0 \\
57 \pm 3.4\end{array}$ & $\begin{array}{l}38 \pm 3.2 \\
40 \pm 4.5\end{array}$ & $\begin{array}{l}7.42 \pm 0.04 \\
7.31 \pm 0.04^{4}\end{array}$ & $\begin{array}{l}23 \pm 0.8 \\
19 \pm 14^{4}\end{array}$ & $\begin{array}{l}14.8 \pm 0.54 \\
(140)\end{array}$ & $57 \pm 3.7$ & $38 \pm 3.3$ & $5 \pm 1.1$ \\
\hline $\begin{array}{l}\text { Warm humidi- } \\
\text { fied }\end{array}$ & $\frac{10}{10}$ & $\begin{array}{l}2.2 \pm 0.9 \\
1.6 \pm 0.9\end{array}$ & $\begin{array}{l}93 \pm 5.6 \\
86 \pm 6.6^{1}\end{array}$ & $\begin{array}{l}34 \pm 0.7 \\
32 \pm 0.9^{4}\end{array}$ & $\begin{array}{l}69 \pm 3.5 \\
68 \pm 3.5\end{array}$ & $\begin{array}{l}34 \pm 1.7 \\
32 \pm 2.0\end{array}$ & $\begin{array}{l}7.46 \pm 0.02 \\
7.42 \pm 0.02\end{array}$ & $\begin{array}{l}23 \pm 0.9 \\
21 \pm 0.5^{4}\end{array}$ & $\begin{array}{c}11.3 \pm 0.47 \\
(148)\end{array}$ & $71 \pm 2.8^{4}$ & $26 \pm 1.5^{5}$ & $3 \pm 1.7$ \\
\hline
\end{tabular}

'Statistical analysis done using $\chi^{2}$ for survival, paired $t$ test when comparing paired values, and Student's $t$ test when comparing mean values from groups.

' $\mathrm{CVP}$, central venous pressure: $\mathrm{BP}$, arterial pressure: $\mathrm{HCT}$, hematocrit: $\mathrm{PaO}_{2}$, arterial oxygen tension; $\mathrm{PaCO}_{2}$, arterial carbon dioxide tension: $\mathrm{pHa}$, arterial pH: $\mathrm{HCO}{ }_{3}$, calculated bicarbonate.

${ }^{3}$ Mean \pm S.E

$4 P<0.05$.

${ }^{5} P<0.01$.

"i $P<0.001$ 
remained normal in the control and the warm humidified groups due to a decrease in arterial carbon dioxide tension. Mean pHa declined significantly in the cold nebulized group and modestly in the warm nebulized group. Mean CVP and arterial oxygen tension remained stable in all groups. The dynamic lung compliance decreased in the controls (mean decrease, $49 \%$ ) but remained stable in the ventilated rabbits (mean increase, $3 \%$; not shown in Table 1).

\section{OUTCOME (TABLE I)}

All rabbits in the control and warm humidified groups survived the study. Six of II rabbits ventilated with air circuited through a nebulizer at $22^{\circ} \mathrm{C}$ and three of 11 ventilated with air circuited through a heated nebulizer died before completion of study.

\section{PULMONARY MORPHOLOGY}

Lung sections from one of 10 controls showed interstitial widening and modest infiltration with mononuclear and polymorphonuclear cells. In contrast, nine of 11 rabbits in the cold nebulized group had interstitial widening and infiltration $\left(\chi^{2}=5.2 ; P=\right.$ $<0.025$ ), and six of 11 rabbits in the warm nebulized group developed interstitial widening and infiltration $(P-n s)$; three of these had intraalveolar edema. Three of 10 rabbits ventilated with warm humidified air developed interstitial edema ( $P$-ns); only one had intraalveolar edema. Grading of pathologic lesions was not attempted because of the inherent inaccuracies of this subjective analysis and the wide variation in the degree of damage, even within groups.

One of six rabbits sacrificed soon after receipt had histologic evidence of an inflammatory reaction in the lung. There was no evidence of infection in the other five rabbits; hence, it was assumed that the majority of rabbits were free of infection.
PULMONARY MORPHOMETRY (TABL.E. I: FI(i. 2)

The percentage of area occupied by alveolar space, interstitium. and edema fluid in lung sections obtained from all rabbits in the four groups is shown in Table 1. Photomicrographs of representative sections of lungs are shown in Figure 2. The cold nebulized group had a significant reduction in mean air space and an increase in mean interstitial space and mean edema fluid when compared to controls. The warm nebulized group had no significant morphometric changes, but the warm humidified group actually fared better than the controls in terms of a significant increase in mean air space and decrease in interstitial thickness. The mean pulmonary arterial wall thickness was significantly greater in both cold and warm nebulized groups than in controls (Table 1). Mean pulmonary vascular wall thickness of rabbits ventilated with warm humidified air was similar to that of the controls.

\section{DISCUSSION}

Pulmonary damage that follows IPPV has been attributed to oxygen $(1,7,19,26,27,35)$, barotrauma $(19,20,36,37)$, pulmonary edema (4), and infection or the presence of the endotracheal tube (6). Additional factors, like inspired air temperature and particulate water content, may also play a role in the production of this pulmonary parenchymal damage. Otter et al. (30) produced massive pulmonary edema of the left lung in mongrel dogs by instilling large quantities of fresh water into that lung while maintaining normal oxygenation by ventilating the right lung. Acute pulmonary edema due to near drowning has been reported to be aggravated by IPPV (16). Although these two situations are not comparable to that situation where nebulized water is delivered during IPPV, tracheal instillation of small quantities of fresh water in lightly anesthetized, supine sheep has been shown to produce

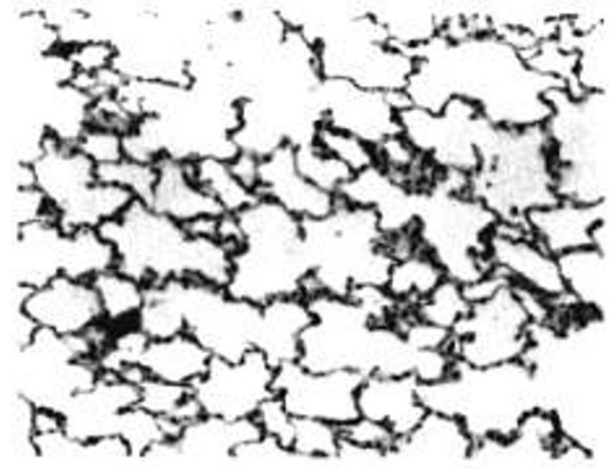

CONTROLS

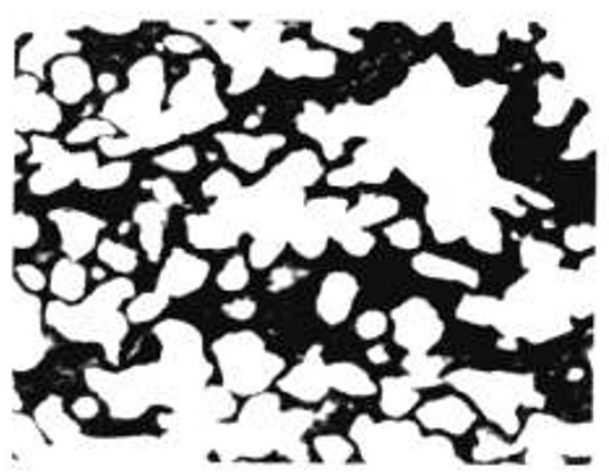

IPPV-WARM NEBULIZED'AIR

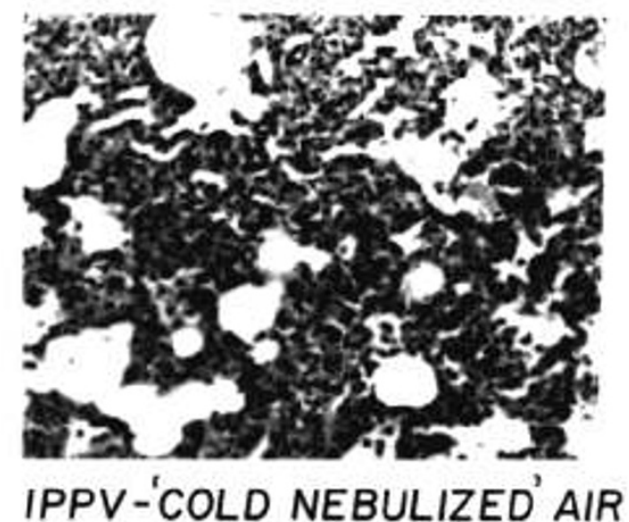

IPPV-COLD NEBULIZED AIR

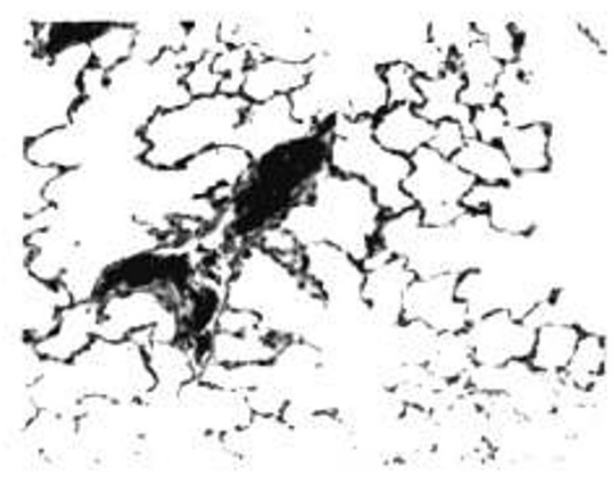

IPPV'WARM HUMIDIFIED'AIR

Fig. 2. Representative lung sections from four groups of rabbits. The interstitial widening after IPPV with warm nebulized air and interstitial widening and intraalveolar edema after IPPV with cold nebulized air in contrast with the normal lung structure of control and warm humidified group. Data obtained from morphometric analysis are indicated in Table 1. 
reflex pulmonary hypertension (5). This was prevented by premedication with atropine sulphate, but vagotomy had no effect, suggesting that the hypertension was the result of a local reflex. In the present study, medial thickness of the small muscular pulmonary arteries was increased in both groups of rabbits ventilated with air nebulized with water when compared to that of the arteries from control and warm humidified groups, in both of which inspired air was free of particulate water. Whether this occurs in the human lung subjected to similar insult is conjectural.

It is pertinent to note that mean medial thickness of pulmonary arteries in the control rabbits in this study of $11.8 \%$ was higher than the $7 \%$ reported for human lung by Wagenvoort and Wagenvoort (39). This could be due to species difference or to a difference in the preparation of the lung for morphometry. The pulmonary arteries of the lungs studied by us were not perfused in the manner of Wagenvoort and Wagenvoort because our preliminary work showed that this resulted in significant but unpredictable widening of the vascular lumen.

Although methods are available to increase water content of inspired air to saturation point $(3,14,15,18,21)$, there is little information about the optimum humidity required during IPPV (10,38). Using scanning electron microscopy, Tsuda et al. (38) demonstrated marked injury to the cilia and degeneration of mucus droplets in trachea and primary bronchi of dogs when dry gas was used. Inhalation of air with relative humidity of $100 \%$ at $35^{\circ} \mathrm{C}$ for over $3 \mathrm{hr}$ resulted in injury to the cilia in the tertiary bronchi, whereas inhalation of air with a relative humidity of $100 \%$ at $30^{\circ} \mathrm{C}$ did not have a deleterious effect. The differing responses in the groups were attributed to the water content of the inspired air.

In this study, we noted significant hypotension and modest acidemia in all groups of rabbits. This might have been due to pentobarbitone anesthesia which has been shown to reduce cardiac output and blood pressure in healthy young rabbits (E. John, personal observation), as well as in dogs (13). However, the two groups of rabbits ventilated with air containing droplets of water were compromised to a greater extent than the group ventilated with humid air free of water droplets and the controls. Nine of 22 rabbits in the nebulized groups died before completion of the study, whereas none of the rabbits in the other two groups succumbed $(P<0.005)$. They were also more acidemic and hypotensive towards the end of the study period (Table 1). Pulmonary morphometry revealed significantly greater pulmonary arterial wall thickness, decreased alveolar space, and increased interstitial and intraalveolar edema in the nebulized groups of rabbits when compared to controls and those ventilated with humidified air. These data suggest that delivery of droplets of water to the lung may be the common factor responsible for the metabolic and pulmonary compromise in the rabbits in whom air nebulized with water was used for IPPV. The sequence of events is unclear, and further work is needed to determine whether the pulmonary vasoconstriction preceeded or succeeded the systemic hypotension and acidemia.

The temperature of the inspired air during IPPV has been randomly selected by most groups; no attempt has been made to study the effect on the lung of varying temperature in the presence of specified water content. Nagao et al. (25), studying excised rabbit lung that was mechanically ventilated, noted linear increase in lung recoil with decreasing temperatures below $22^{\circ} \mathrm{C}$; there were no significant changes with temperatures between 22 and $37^{\circ} \mathrm{C}$. We looked at the effect on the rabbit lung of moist air delivered at 22 and $36^{\circ} \mathrm{C}$ only in the nebulized groups. The pulmonary parenchymal changes obtained using TAS were not significantly different from each other. However, the trend was interesting. The cold nebulized group had more interstitial and intraalveolar edema and correspondingly less air space compared to warm nebulized group (Table 1) suggesting that the lower temperature $\left(22^{\circ} \mathrm{C}\right)$ may have contributed to the genesis of pulmonary damage.

Data obtained from this study suggest that, under conditions of this experiment, lung damage after IPPV is least when inspired air is humidified and warmed to 35 to $36^{\circ} \mathrm{C}$ and when formation and delivery of water droplets to the respiratory airways is avoided. Parenchymal damage to the human lung may well be reduced by taking precautions to maintain inspired air temperature close to body temperature and to prevent particulate water from entering the lungs.

\section{REFERENCES AND NOTES}

I. Banerjee. C. K.. Girling. D. J., and Wigglesworth. J. S.: Pulmonary fibroplasia in newborn babies treated with oxygen and artificial ventilation. Arch. Dis. Child.. 47: 509 (1972)

2. Barber, R. E. Lee. J., and Hamilton. W. K.: Oxygen toxicity in man. A prospective study in patients with irreversible brain damage. N. Engl. J. Med.. 283: 1478 (1970)

3. Benveniste. D.. and Poul Pedersen. J. E.: (entralized system of humidification for respiratory treatment. Anaesthesia. 31: 421 (1976).

4. Brown. E. R.. Stark. A.. Sosenko. I.. Lawson. E. E.. and Avery, M. E.: Bronchopulmonary dysplasia: possible relationship in pulmonary edema. J. Pediatr. 92: 982 (1978)

5. Colebatch. H. J. H., and Halmagyi, D. F. J.: Retlex pulmonary hypertension of fresh-water aspiration. J. Appl. Physiol.. 18: 179 (1963).

6. Daily, W. J. R., and Northway. W. H.: Perspectives in mechanical ventilation. Adv. Pediatr. I8: 253 (1971).

7. deLemos, R., Wolfsdorf. J.. Nachman. R.. Block, A. J., Leiby. (j.. Wilkinson. H. A., Allen. T., Haller. J. A.. Morgan. W., and Avery, M. E.: Lung injury from oxygen in lambs: the role of artificial ventilation. Anesthesiology. $30: 6(09$ (1969).

8. Dery. R.: Water balance of the respiratory tract during ventilation with a gas mixture saturated at body temperature. (an. Anaesth. Soc. J.. 20: 719 (1973).

9. Douglas. F. G.. Chong. P. Y.. and Finlayson. D. C.: Eflect of artificial ventilation on lung mechanics in dogs. J. Appl. Physiol.. 37; 324 (1974).

10. Editorial: Importance of humidity control during anesthesia. Br. J. Anaesth.. 42: $278(1970)$

11. Editorial views: mechanical ventilation of the newborn. Anesthesiology. .4: 116 (1971).

12. Edwards, D. K.. Dyer. W. M. and Northway. W. H.: Twelve years experience with bronchopulmonary dysplasia. Pediatrics, 59: 839 (1977)

13. Ericsson. B. J.: Effect of pentobarbital sodium anesthesia. as judged with aid of radioactive carbonized microspheres, on cardiac output and its fractional distribution in the dog. Acta (hir. Scand.. 1.37: 613 (1971).

14. Geervarghese. K. P.. Aldrete. J. A., and Patel. T. C.: Inspired air temperature with immersion heater humidifiers. (urr. Res. Anesth. Analg. 55: 331 (1976)

15. Graff. T. D.: Humidification: indications and hazards in respiratory therapy. Curr. Res. Anesth. Analg., 54: 444 (1975).

16. Haddy, T. B., and Disenhouse, R. B.: Acute pulmonary edema due to neardrowning in fresh water. J. Pediats. 44: $565(1954)$.

17. Halmagyi. D. F. J., and Colebatch. H. J. H.: Ventilation and circulation after fluid aspiration. J. Appl. Physiol.. 16: 34 (1961).

18. Hayes, B. and Robinson. J. S.: An assessment of methods of humidification of inspired gas. Br. J. Anaesth.. 42: 94 (1970).

19. Horsky, P.: Lesions pulmonaries de la ventilation artificielle et de loxygenotherapie: etude experimentale chet le chat. Respiration. 34: 278 (1977).

20. John, E.: The effect of intermittent positive pressure ventilation on rabbit lung Aust. Paediatr. J., 12: 229 (1976).

21. Klein. E. F.. Shah. D. A.. Shah. J. J.. Modell. J. H., and Desautels. D. Performance characteristics of conventional and prototype humiditiers and nebulizers. Chest, 64: 690, (1973).

22. Lang, V. O.: Zur Problematic einer optimalen anwarmung und anfeuchtung von atemgasen bei kunstlicher beatmung und atemhilfs therapie. Anaesthesist. 28 ; 125 (1979).

23. Langston. C.. and Thurlbeck. W. M.: The use of simple image analysers in lung morphometry. J. Micros. (Oxf.). 114: 89 (1978).

24. Meyer, J. A.: Mechanical support of respiration. Surg. Clin. N. Am.. 54: 1115 (1974).

25. Nagao, K.. Ardila. R., Sugiyama. M.. and Hildebrandt. J.: Temperature and hydration: factors affecting increased recoil of excised rabbit lung. Respir Physiol., 29: 11 (1977).

26. Nash. G.. Blennerhassett. J. B.. and Pontoppidan. H.: Pulmonary lesions associated with oxygen therapy and artificial ventilation. N. Engl. J. Med.. 276: 368 (1967)

27. Nash, G.. Bowen, J. A.. and Langlinais, P. C.: "Respirator lung" a misnomer. Arch. Pathol.. 2l: 234 (1971).

28. Nelson. D.. and McDonald. J. S.: Heated humidification, temperature control. and "rainout" in neonatal ventilation. Perinatol. Neonatol., 1: 23 (1977).

29. Northway, W. H., Rosan, R. C.. and Porter, D. Y.: Pulmonary disease following respirator therapy of hyaline membrane disease. N. Engl. J. Med., 276: 35 (1967)

30. Otter, G. D. Van Nouhuys, F., and Bakker. N. J .. Investigations on the cause of death in fresh water drowning. Acta Physiol. Pharmacol. Neerl., 4: 415 (1960)

31. Pontoppidan, H. Wilson. R. S.. Rie. M. A.. and Schneider. R. C.: Respiratory intensive care. Anesthesiology. 17: 96 (1977).

32. Proctor, D. F.: State of the art. The upper airways. I. Nasal physiology and defense of the lungs. Am. Rev. Respir. Dis., 115: 97 (1977). 
33. Reynolds. E. O. R.. and Taghizadeh. A.: Improved prognosis of infants mechanically ventilated for hyaline membrane disease. Arch. Dis. Chld.. 49: 505 (1974).

34. Serra, J., and Müller, H.: The Leitz Texture Analyser System. Theoretical bases and technical realization. Sci. Tech. Inf., Suppl., I: 4 (1974).

35. Singer, M. M., Wright. F.. Stanley, L. K., Roe, B. B.. and Hamilton. W. K Oxygen toxicity in man: a prospective study in patients after open heart surgery. N. Engl. J. Med.. 283: 1473 (1970).

36. Stocks, J., and Godfrey. S.: The role of artificial ventilation, oxygen and CPAP in the pathogenesis of lung damage in neonates: assessment by serial measurements of lung function. Pediatrics. 57: 352 (1976).

37. Taghizadeh, A.. and Reynolds, E. O. R.: Pathogenesis of lung bronchopulmonary dysplasia following hyaline membrane disease. Am. J. Pathol., \&2: 241 ( 1976). 38. Tsuda, T., Noguchi. H., Takumi, Y.. and Aochi. O.: Optimum humidilication of air administered to a tracheostomy in dogs. Scanning electron microscopy and surfactant studies. Br. J. Anaesth., 49: 965 (1977).

39. Wagenvoort, C. A., and Wagenvoort, N.: Pathology of pulmonary hypertension. (John Wiley \& Sons. Inc.. New York. 1977).

40. Requests for reprints should be addressed to: Dr. George Cassady, Professor. Department of Pediatrics. Division of Perinatal Medicine, University of Alabama School of Medicine, Birmingham. AL 35294 (USA).

41. Received for publication September 6. 1979

42. Accepted for publication March 4. 1980.

Copyright (1) 1980 International Pediatric Research Foundation, Inc. $0331-3998 / 80 / 1411-1186 \$ 02.00 / 0$ 